\title{
Clinical Diagnosis of Leptospirosis in Malaysia: Challenges and Prospects
}

\author{
Bashiru Garba ${ }^{1,2 *}$ and Ayan Aden Moussa ${ }^{2}$ \\ ${ }^{I}$ Department of Veterinary Public Health and Preventive Medicine, Faculty of Veterinary Medicine, Usmanu Danfodiyo University Sokoto. 840212, \\ Sultan Abubakar Road, City Campus Complex, Sokoto, Sokoto State, Nigeria \\ ${ }^{2}$ Institute for Medical Research, SIMAD University, Mogadishu, Somalia \\ *Corresponding author's Email: garba.bashiru@udusok.edu.ng; (DORCiD: 0000-0001-7295-9665
}

\begin{abstract}
Leptospirosis is a neglected emerging zoonosis occurring both in urban environments and rural regions worldwide. During occupational and recreational activities, individuals who directly or indirectly contact the urine of infected animals are at a high risk of infection. Southeast Asia is reported to have the highest incidence of leptospirosis in the world. The disease is endemic in Malaysia and has consistently caused outbreaks among humans with severe outcomes. Early diagnosis is vital for commence treatment thereby minimizing the harmful effects of the disease. It also allows the implementation of measures to control the spread to humans and the environment. In this article, an attempt was made to review the current diagnostic methods including challenges faced by healthcare service providers during the diagnosis of acute cases, as well as the emerging technologies used for early and accurate diagnosis. The review also highlighted innovative ideas that can be integrated into developing practical solutions, including the crucial roles of the patients, reservoir hosts, and the environments that harbor the bacteria.
\end{abstract}

Keywords: Emerging zoonoses, Laboratory diagnosis, Leptospirosis, Malaysia, Neglected tropical disease

\section{INTRODUCTION}

Leptospirosis is an endemic bacterial infection affecting predominantly tropical and subtropical regions of the world, particularly those living in rural areas and urban slums (Hagan et al., 2016; Sukeri et al., 2018). The incidence of the disease is at the highest rate in the Southeast Asia region and major outbreaks were currently recorded in Indonesia, Malaysia, and India (Garba et al., 2017; Boey et al., 2019). Pathogenic leptospires have become widespread as a result of the persistent colonization of the renal tubules of reservoir hosts, which constitute a serious public health problem (Haake and Levett, 2015). The bacteria is a spirochaete belonging to the Leptospiraceae family. It is mostly transmitted to humans when they directly or indirectly have contact with the urine of infected domestic or wild animal reservoirs, as well as environments contaminated with the urine of the rats as reservoir hosts (Rattus rattus and Rattus norvegicus species).

The first human case of severe leptospirosis in Malaysia was diagnosed in 1927 (El Jalii and Bahaman, 2004). In recent years, an increase in the incidence of human leptospirosis in Malaysia has been observed to coincide with severe flooding in some major states, including Kelantan and Selangor (Garba et al., 2018). Similarly, over 18 antigenically distinct serovars have been identified among humans and animals in Malaysia based on the gold standard microscopic agglutination tests (Daud et al., 2018; Rahman et al., 2018).

Generally, diagnosis is based on laboratory results. However, the laboratory diagnosis on its own may face some challenges due to the non-specific clinical presentation of the disease (Kishimoto et al., 2004). This frequent misdiagnosis and the lack of highly competent diagnostics is an important contributor to the under-reporting of the burden of leptospirosis including death, ill-health due to diseases, cost of treatment, and prevention among others. This under-reporting has serious implications on the planning and evaluation of disease prevention and control programs. leptospiral culture and the microscopic agglutination test (MAT) are two of the most reliable confirmatory tests for detection and identification of infecting serovar (Miotto et al., 2018). However, MAT is less sensitive in the early phase of the disease, it is time-consuming and difficult to perform due to the large number of live antigens required (19 recommended by the WHO), it requires a high level of technical expertise to conduct and interpret the result, as well as the potential risk of infection during handling of live antigens/leptospires (Picardeau et al., 2014). Therefore, the only 
sensitive and specific test suitable for the diagnosis of acute infection is the polymerase chain reaction (PCR) (Musso and La Scola, 2013). Unfortunately, the PCR is not readily available in most of the highly endemic areas, while the serological reference method by MAT is restricted to reference laboratories (Picardeau, 2013).

Similar to most tropical diseases, early diagnosis of leptospirosis is essential before the commencement of treatment (Jesse et al., 2018; Alia et al., 2019; Garba et al., 2019). This is important because Leptospira infections are characterized by high morbidity and mortality. So using initial and fast diagnostic tests for detection of leptospirosis beside disease surveillance and case confirmation can be more notable than ever. While testing of symptomatic individuals is paramount for the detection of active cases to guide public health agencies to strengthen their surveillance systems, the need for routine diagnosis should not be limited to only symptomatic infections. This is because a high proportion of individuals infected with leptospirosis are asymptomatic while some may develop chronic renal colonization characterized by tubulointerstitial nephritis and kidney fibrosis with transient leptospiral shedding that may continue to serve as a source of contamination to the environment (Haake and Levett, 2015; Yang et al., 2015; Riefkohl et al., 2017).

Current guidelines according to the Malaysian Ministry of Health recommends screening for leptospirosis in all individuals presenting fever and history of exposure or suspected exposure to any potential risk factor for leptospirosis (Lim et al., 2011; Rafizah et al., 2013). The Ministry of Health guidance also emphasizes the need to educate individuals on the transmission mode of the disease, particularly with regards to job-related precautionary measures and the importance of hygiene and sanitation. However, recommendations by public health authorities in different countries may vary according to the predominant serovars and their virulence, prevalence of the disease, and availability or lack of laboratory capacity (sensitive PCR detection is lacking in resource-limited endemic countries). This review is undertaken to highlight the common challenges encountered during the laboratory diagnosis of leptospirosis in Malaysia. The article emphasizes the need for early diagnosis of leptospirosis, which usually guides chemotherapeutic intervention to reduce the burden of illness and the financial cost incurred as a result of long-term hospitalization.

\section{Epidemiology and burden of leptospirosis}

The global distribution and incidence of leptospirosis have dramatically increased in recent years. Ironically, the actual numbers of leptospirosis cases are grossly under-reported due to frequent misdiagnosis. The recent estimate indicates that in every 100,000 population, there is annual morbidity of 14.77 cases and mortality of 0.84 (Costa et al., 2015). However, the World Health Organization Leptospirosis Burden Epidemiology Reference Group (LERG) estimates that during an epidemic cases can soar to 100 or more per 100,000 individuals while acknowledging that the disease is grossly under-reported due to the lack of appropriate diagnostic laboratory services especially because the reference serological method (Microscopic Agglutinination Test MAT) is only restricted to reference laboratories (Musso and La Scola, 2013). Similarly, extreme weather events associated with global climate change (such as torrential rainfall leading to flooding) are also fueling the incidence rate and have resulted in an upsurge in the number of cases, as well as the magnitude of the outbreaks. Leptospirosis has been reported in most parts of the world, however, the disease is mostly endemic in humid subtropical and tropical countries and outbreaks often follow heavy rainfall or flooding.

In the year 2014, Malaysia experienced the highest number of reported leptospirosis cases due to the devastating flood that affected most of the states (Benacer et al., 2016; Garba et al., 2017). The number of reported cases not only increased but also explosive outbreaks occurred as the disease spread to new areas (Neela et al., 2019). Although the exact pathogenic serovars causing the disease in humans in Malaysia are yet to be ascertained, the number of cases and sporadic outbreaks are all indicative of the persistence of the bacteria.

The increase in the number of cases is thought to be linked to indirect transmission following flooding or exposure to contaminated water during recreational activities, that are caused by animal reservoirs inhabiting forested areas, recreational parks, and households (Azhari et al., 2018). The persistent excretion of viable leptospires in the environment, as well as the warm humid weather in Malaysia, are thought to be responsible for the survival of these pathogens in the environment.

\section{The transmission cycle of Leptospira}

As earlier highlighted, the most important source of human infection with pathogenic Leptospira is the rodent reservoirs (Hasoun et al., 2017; Boey et al., 2019). However, other domestic and wild canine species and herbivores also harbor certain pathogenic serovars, that can contaminate the living environment, thereby predisposing humans to possible infection (Haake and Levett, 2015). These mammals harbor the bacteria in their kidneys for long periods without showing visible signs of ill health. Out of these species, the primary reservoir hosts in Malaysia are the Rattus rattus and Rattus norvegicus. They are considered the principal vector responsible for Leptospira transmission and epidemics. Other important reservoirs in Malaysia are squirrels, shrews, dogs, and buffaloes (Hartskeerl and Terpstra, 1996; Ellis, 2015; Azhari et al., 2018). 
The majority of human cases follow indirect exposure to soil and water contaminated with infected urine (Benacer et al., 2016; Neela et al., 2019). This usually follows heavy rainfall or flooding, particularly in endemic countries like Malaysia. Other important ways through which humans acquire infection are direct contact with mucous membranes or abraded skin as well as prolonged stay in contaminated water.

\section{Clinical features}

Generally, the clinical course of leptospirosis is variable with severity depending on the virulence of the infecting serovar, the dose of the inoculum, and the immune competence of the patient (Vitale et al., 2017). The majority of patients suffer from only mild self-limiting or subclinical illness. However, severe and potentially fatal leptospirosis can occur in rare cases with complications (Haake and Levett, 2015). The signs of illness that manifest after an incubation period of 2-10 days are characterized by abrupt onset of fever, myalgia, and headache (Laras et al., 2002). Other generalized signs of illness are ocular infection which has been reported in 55\% of patients (Vanasco et al., 2008), nonproductive cough, nausea, vomiting, and diarrhea in rare cases (Katz et al., 2001). Leptospirosis occurs in two forms with acute bacteremia in the initial phase followed by an immune phase (Levett, 2001). The disease can occasionally become complicated with jaundice as a result of degenerative changes in the liver and renal failure due to a dysfunctional kidney. This is referred to as Weil's disease, which is a severe form of leptospirosis affecting multiple organs. Potentially fatal leptospirosis characterized by pulmonary hemorrhagic syndrome is common among some patients with a mortality rate of up to $70 \%$.

\section{Diagnosis of leptospirosis}

When Leptospires invade the human body, the immune system comprising of an innate arm responds immediately while an adaptive component develops much later (Garba et al., 2018). Immunity against Leptospira infection is thought to be humoral based. However, studies have also demonstrated the involvement of the long-term cell-mediated immune response. The diagnosis of leptospirosis is essential not only for the clinical management of patients, but also for intervention, especially during outbreaks, epidemiological surveillance, and monitoring (McBride et al., 2005). Laboratory confirmation has become a vital part of diagnosing leptospirosis and the most reliable means of determining the prevalence of the disease. Early laboratory confirmation of leptospirosis before the onset of antibodies is challenging and often depends on the detection or isolation of the bacteria or its polysaccharide antigens. One of the major barriers to the early diagnosis of leptospirosis is the misconception and incomplete knowledge of the pathogenesis of the disease (Bharti et al., 2003). The multiplicity of serovars, variability in virulence, and distribution from region to region, also constitute a significant drawback.

Considerable resources have been deployed in leptospirosis research to fully understand the pathogenomics of leptospirosis with the aim of developing effective vaccines and diagnostics. Nevertheless, efficacious vaccines that can render protection against multiple serovars have proven to be elusive. In the absence of effective vaccines, a breakthrough in diagnosis at an early stage is desired for timely etiological investigation, clinical intervention, and disease control.

\section{Methods used for routine diagnosis of leptospirosis}

Due to the non-specific nature of clinical leptospirosis and the full range of signs associated with acute infection, as well as the generalized nature of laboratory findings, confirmatory diagnosis of leptospirosis is based on specific laboratory tests. However, other routine blood tests, including renal and liver function tests, and x-ray are conducted because of the multiple organ system involvements (Russell et al., 2018).

\section{Dark field microscopic demonstration}

Viable Leptospira can be detected by dark-field microscopic examination using blood or urine samples from sick patients, including the early phase of the disease (Levett, 2001). However, the sensitivity is generally low and an erroneous conclusion can be made due to misconception about the difference between leptospires and fibrin threads. Additionally, leptospires can only be found in the blood smears for short periods after infection. Hence, considerable expertise is needed in terms of sampling and examination of the specimen using the microscope.

\section{Bacterial isolation}

Leptospiral isolation using clinical samples like blood, urine, and kidney tissues is considered one of the most reliable methods of diagnosis. However, this approach is not suitable for the clinical purpose during hospitalization, rather for surveillance and epidemiological studies. Blood samples for culture are better collected during the leptospiremia stage after the onset of infection. Successful isolation of leptospires from clinical samples depends on the quality of the samples and the time of collection. Because leptospires persist in the blood for short periods, blood sampling a few days (1-7 days) after the commencement of infection is the most ideal (Bourhy et al., 2010). In this 
regard, blood plasma with anticoagulant can be used for isolation on the Ellinghausen, McCullough, Johnson and Harris EMJH medium, or the Wuthiekanun media (Wuthiekanun et al., 2007). Moreover, due to frequent kidney colonization by leptospires, urine is the most suitable specimen for the isolation of leptospires during the leptospiruria phase. Although the acidic nature of urine tends to affect the viability of the bacteria, hence, the need for centrifugation at room temperature and re-suspension of sediment with media is recommended for successful isolation.

\section{Serological testing}

Serological assays refer to the diagnostic identification of circulating antibodies present in the serum and other body fluids. For the most part, IgM antibodies are used to indicate early infection while long-term infection is identified based on IgG detection. For Leptospira infection, the immune response commences by the fifth or seventh day following infection, and it is evidenced by a slow, low-titer increase in the IgM antibody, which is subsequently replaced by the IgG as the disease progress (Levett, 2001). IgG levels rise rapidly during the secondary infection and can persist for long periods while IgM titers rise very slowly and it is generally short-lived (Adler and Faine, 1978).

Traditionally, the microscopic agglutination test MAT is still considered the standard test for a definitive diagnosis of Leptospira infection in Malaysia (Brandão et al., 1998; Benacer et al., 2016). Unfortunately, MAT is laborious and has low sensitivity, especially in acute infection (Toyokawa et al., 2011). The low sensitivity of MAT, when diagnosing infection during the first week is because the circulating $(\operatorname{IgM})$ antibodies are only detectable one week post-infection, thereby giving false-negative results. In addition, paired sera collected at different time intervals from patients are also required for accurate interpretation of results (Niloofa et al., 2015). Besides, the complete serovars profile has not been established in Malaysia. Moreover, the continuous isolation of environmental strains in Malaysia whose pathogenicity has not been ascertained constitutes a challenge in understanding the circulating serovars in Malaysia. Therefore, confirmatory diagnosis can only be made when paired serum samples indicate a four-fold rise in antibody titer between the acute and convalescent sera. Besides, commercially available tests, such as antibody-based ELISA, dipstick, lateral flow, indirect hemagglutination assay, and latex agglutination test are routinely used in some hospitals (Goris et al., 2013; Picardeau et al., 2014; Tan et al., 2014). Despite the potentials of these assays to detect acute Leptospira infection, they are still not reliable due to the false-positive result and cross-reactivity with other infectious agents (Toyokawa et al., 2011).

\section{Nucleic acid detection}

Polymerase chain reaction assay has been developed globally for robust, sensitive detection of pathogenic Leptospira and other infectious diseases. The method is highly sensitive, rapid, and if optimized can be used for the detection of genetic materials in human clinical samples without the need for isolation of leptospires from clinical specimens, which usually require a couple of weeks to grow (Budihal and Perwez, 2014).

The PCR can be used to detect leptospira using the 16s rRNA gene, which is genus-specific and can detect pathogenic serovars based on the outer membrane protein (LipL32) which is commonly found in all pathogenic strains (Mohd Radi et al., 2018).

Leptospiral DNA can be amplified from the blood, urine, and other body fluids of infected patients. However, the sensitivity of PCR in detecting leptospires from patients' blood during the early stage of the disease is limited because the bacteria are cleared in the blood within 4-7 days following the production of leptospir-specific antibodies (Budihal and Perwez, 2014). As a result, Quantitative real-time PCR is recommended due to its superior sensitivity in the diagnosis of early clinical infection compared to conventional PCR (Rawlins et al., 2014). Real-time PCR (qRT-PCR), is a highly sensitive method for the clinical diagnosis of leptospirosis (Esteves et al., 2018). The assay is based on the generation of different melting curve profiles in the presence of variability in the double-stranded DNA sequence of pathogens (Wittwer et al., 2003). The method has a rapid turnaround time, is relatively inexpensive, exhibits high sensitivity and specificity, and significantly reduces the risk of contamination (Tong and Giffard, 2012). Moreover, high resolution melting (HRM) analysis, which is based on the SYBR green chemistries has become the preferred method for clinical diagnosis of leptospirosis. The technique has the potential to significantly reduce the risk of contamination, has high sensitivity and specificity, and with a rapid turnaround time (less than 2 hours) (Esteves et al., 2018).

\section{Early clinical diagnosis of leptospirosis}

The traditional practice in most laboratories during the diagnosis of leptospirosis is the combination of PCR and MAT. After the manifestation of clinical signs, the bacteria can be detected in serum and plasma for 4-5 days (De Brito et al., 2018). During this early stage, nucleic acid amplification can be used to diagnose the infection while at the end of the acute phase of infection serology using MAT can be employed as the method of choice for diagnosis. Molecular diagnosis based on quantitative PCR qPCR has gradually become popular, especially during the acute stage of leptospirosis. The technique is highly sensitive with a reasonable turnaround time. Studies have also reported that the 
period within which the bacteria remains in blood circulation is longer (15 days) than initial thought, hence higher chances of detection (Agampodi et al., 2012).

\section{Diagnostic challenges}

Due to the non-specific clinical presentation of leptospirosis, accurate and early diagnosis is imperative as a means of differentiating it from other diseases, such as dengue and malaria. This is essential for the clinical management of the disease, as well as surveillance. Currently, symptomatic and supportive management of infection is dependent on accurate diagnostics. Hence, once the diagnosis is performed unsuccessfully, problems ensue. Since most Leptospira infections are mild and asymptomatic, the majority of the patients do not visit the hospital, which accounts for the severe neglect the disease suffers (Cosson et al., 2014). In Malaysia, the Ministry of Health recommends that patients having a MAT titer of 1:400 with a history of exposure to the risk factors should be considered positive. However, the consensus for confirmatory diagnosis based on MAT is a four-fold rise in antibody titer between the initial samples and convalescent serum which signifies seroconversion. However, the unavailability of patients for the collection of second serum samples in hospitals for evaluation has proven to be a stumbling block. Most of the patients, once they recover and are discharged from the hospital, they hardly avail themselves of the further test.

Moreover, the sensitivity of MAT is affected by the loss of antigenicity of the serovars used for the test due to repeated passage over a long period (Levett, 2001). There is also a need to increase the panel of serovars (19 recommended by the WHO) traditionally included in the MAT test in all hospitals (Musso and La Scola, 2013). This is important because newer serovars are being discovered, especially among rodents and environmental samples. The early and accurate diagnosis of leptospirosis is essential because successful antibiotic treatment is most effective when treatment is initiated early in the course of the disease (Haake and Levett, 2015). The urgency for early diagnosis is supported by the fact that severe and fatal multi-organ disease can develop when intervention is not instituted at the appropriate time (Haake and Levett, 2015; Niloofa et al., 2015).

Moreover, delayed diagnosis is synonymous with a more severe, problematic presentation for case management. It should also be noted that there is a possibility of concomitant infection with leptospirosis, which can increase the difficulty of diagnosis. Some of the factors that are presently hampering the diagnosis of leptospirosis in Malaysia are components of the epidemiological triad, including a large number of serovars in circulation, high number of rodent reservoirs, and the wet humid environment that allow survival of the bacteria in the environment.

\section{Patient}

It is important for individuals living in leptospirosis endemic regions to have a good knowledge of the disease transmission routes, factors that predispose to infection, and clinical signs indicative of leptospirosis (Monahan et al., 2009). During clinical investigations, the patient's history, including the occupation (paddy farmers, abattoir workers, and sewage workers) is very important. The clinical history is important because in most cases individuals are ignorant of the modes of transmission of leptospirosis, and hardly witness rodent activity due to their nocturnal nature. Upon admission, obtaining detailed history is sometimes difficult when the patients are debilitated. In other instances, patients hardly visit the hospital until the infection has advanced, which will make treatment very difficult. Therefore, adequate enlightenment to the risk-prone population is essential.

\section{Pathogen}

Pathogenic Leptospira exhibits variable pathogenicity depending on the dose of the inoculum and the immune status of the patient (Bharti et al., 2003). Although the bacteria can easily be seen under darkfield microscopy, presence of contaminants and other spirochaetes can lead to erroneous conclusions. To make matters worse, studies indicate the existence of new serovars in Malaysia which were previously not known (Zamri et al., 2012). Widely used tests, such as MAT may lack the complete panel of serovars circulating in the population, as well as unavailability of paired serum samples in most cases. Bacterial isolation is challenging due to the fastidious nature of the growth of leptospires and in most cases, not suitable for clinical diagnosis. Moreover, while molecular diagnostic test seems to be highly sensitive and specific, is usually expensive, and hence cannot be accessible in the majority of the endemic areas (Victoriano et al., 2009; Torgerson et al., 2015).

\section{Environment}

Environmental factors cause difficulty in leptospirosis infection diagnosis. The climatic environment and global climate changes seem to be playing significant roles in epidemiological changes of bacteria. This has resulted in the introduction of new strains into human habitation and the multiplying of existing ones. Although isolation of Leptospira from environmental samples is always difficult due to the presence of contaminants, many studies have shown that treatment of the media with 5-fluorouracil has made it possible. The studies also reported that pathogenic leptospires can remain viable in soils many weeks after the infecting event. Similarly, molecular typing of leptospiral DNA from the 
environment specimens revealed similarities between environmental pathogenic Leptospira and the strains incriminated in human clinical infection.

\section{Prospects for the diagnosis of leptospirosis}

In the coming years, leptospirosis will continue to be an important public health problem worldwide. The diagnosis of leptospirosis will equally remain as the most critical issue in the clinical management of leptospirosis cases as the need for the development of highly effective polyvalent vaccines. Researchers tireless efforts are geared toward the development of cost-effective, portable, easy-to-use, and efficient diagnostic tools corresponding to the expanding importance of the disease. In this regard, the efforts of the Ministry of Health Malaysia should be commendable. Due to the understanding that leptospirosis occurs as a result of the complex interactions existing between humans, animals, and their environment, the government has encouraged the health sector to collaborate with other institutions like the veterinary services department, as well as the ministry of environment in a multisectoral engagement based on the onehealth approach to surmount this challenge. The Malaysian government has also developed a national strategy for the control of leptospirosis, which identified a lack of information about leptospirosis as an important factor that is limiting stakeholders' ability to make significant commitments to the national strategy. Similarly, a review of the epidemiology of leptospirosis in Malaysia and recommending priorities for the control of rodent reservoirs and other environmental risk factors were emphasized.

The Malaysian government has also established quality management for control of the disease by monitoring patients' progress, holistic rodent control, improving laboratory investigation, and creating awareness on the importance of the disease. Nevertheless, more still need to be done, especially with too many false-positive results observed in hospitals and other health institutions.

To overcome these challenges, developing cost-effective diagnostic tools suitable for use as the bedside test is important. Similarly, increasing the number of serovars included during MAT will also make serological detection more robust. Furthermore, there is also a need for modifications of existing protocols, especially with regards to the nature and time of collection of specimen, inoculation of available MAT serovars into animal models to re-acquire their virulence, as well as exploring the potentials of recombinant antigens for application in early diagnosis.

\section{CONCLUSION}

To date, the most popular method for the clinical diagnosis the leptospirosis is the MAT, followed by culture, serology, and molecular detections. These methods are fraught with inconsistencies and require a high level of expertise, as well as a significant amount of time to produce a reliable result. Similarly, the real-time polymerase chain reaction method, though very sensitive and specific for diagnosis in the early stage, requires high technical skills. Nevertheless, recent advances in molecular and serological diagnostic techniques have shown great promise, as evidenced by the improved sensitivity and specificity of many diagnostic tests for other diseases.

\section{DECLARATIONS}

\section{Authors' contribution}

Bashiru Garba conceptualize the idea and initiated the manuscript drafting. Both authors (Bashiru Garba and Ayan Aden Moussa) contributed to the editing and production of the final draft.

\section{Competing interests}

The authors declare no conflict of interest in this review

\section{Acknowledgments}

The authors wish to thank Professor Zunita Zakaria of the Institute of Bioscience, Universiti Putra Malaysia for her kind assistance and guidance during the drafting of this manuscript.

\section{Ethical consideration}

Ethical issues (including plagiarism, consent to publish, misconduct, data fabrication and/or falsification, double publication and/or submission, and redundancy) have been checked by the authors.

\section{REFERENCES}

Adler B, and Faine S (1978). The antibodies involved in the human immune response to Leptospiral infection. Journal of Medical Microbiology, 11: 387-400. DOI: https://www.doi.org/10.1099/00222615-11-4-387

Agampodi SB, Matthias MA, Moreno AC, and Vinetz JM (2012). Utility of quantitative polymerase chain reaction in Leptospirosis diagnosis: Association of level of Leptospiremia and clinical manifestations in Sri Lanka. Clinical Infectious Disease, 54: 1249. DOI: https://www.doi.org/10.1093/CID/CIS035. 
Alia SN, Joseph N, Philip N, Azhari NN, Garba B, Masri SN, Sekawi Z, and Neela VK (2019). Diagnostic accuracy of rapid diagnostic tests for the early detection of leptospirosis. Journal of Infection and Public Health, 12: 263-269. DOI: https://www.doi.org/10.1016/j.jiph.2018.10.137.

Azhari NN, Ramli SN, Joseph N, Philip N, Mustapha NF, Ishak SN, Mohd-Taib FS, Nor SM, Yusof MA, Sah SA et al. (2018). Molecular characterization of pathogenic Leptospira sp. in small mammals captured from the human leptospirosis suspected areas of Selangor state, Malaysia. Acta Tropica, 188: 68-77. DOI: https://www.doi.org/10.1016/j.actatropica.2018.08.020.

Bahaman AR, Ibrahim AL, Stallman ND, and Tinniswood RD (1988). The bacteriological prevalence of leptospiral infection in cattle and buffaloes in West Malaysia. Epidemiology and Infection, 100: 239-46. DOI: https://www.doi.org/10.1017/s0950268800067376

Benacer D, Thong KL, Verasahib KB, Galloway RL, Hartskeerl RA, Lewis JW, and Mohd Zain SN (2016). Human Leptospirosis in Malaysia. Asia Pacific Journal of Public Health, 28: 290-302. DOI: https://www.doi.org/10.1177/1010539516640350.

Bharti AR, Nally JE, Ricaldi JN, Matthias MA, Diaz MM, Lovett MA, Levett PN, Gilman RH, Willig MR, Gotuzzo E et al. (2003). Leptospirosis: A zoonotic disease of global importance. Lancet Infectious Disease, 3: 757-771. DOI: https://www.doi.org/10.1016/S1473-3099(03)00830-2.

Boey K, Shiokawa K, and Rajeev S (2019). Leptospira infection in rats: A literature review of global prevalence and distribution. PLoS Neglected Tropical Diseases, 13: e0007499. DOI:10.1371/journal.pntd.0007499.

Bourhy P, Collet L, Clément S, Huerre M, Ave P, Giry C, Pettinelli F, and Picardeau M (2010). Isolation and characterization of new Leptospira genotypes from patients in Mayotte (Indian Ocean). PLoS Neglected Tropical Diseases, 4: e724. DOI: https://www.doi.org/10.1371/journal.pntd.0000724.

Brandão AP, Camargo ED, da Silva ED, Silva MV, and Abrão RV (1998). Macroscopic agglutination test for rapid diagnosis of human Leptospirosis. Journal of Clinical Microbiology, 36: 3138-3142. Available at: https://pubmed.ncbi.nlm.nih.gov/9774553/

Budihal SV, and Perwez K (2014). Leptospirosis diagnosis: Competancy of various laboratory tests. Journal of Clinical Diagnostic Research, 8: 199. DOI: https://www.doi.org/10.7860/JCDR/2014/6593.3950.

Cosson JF, Picardeau M, Mielcarek M, Tatard C, Chaval Y, Suputtamongkol Y, Buchy P, Jittapalapong S, Herbreteau V, and Morand S (2014). Epidemiology of Leptospira transmitted by rodents in Southeast Asia. PLoS Neglected Tropical Diseases, 8: e2902. DOI: https://www.doi.org/10.1371/journal.pntd.0002902.

Costa F, Hagan JE, Calcagno J, Kane M, Torgerson P, Martinez-Silveira MS, Stein C, Abela-Ridder B, and Ko AI (2015). Global Morbidity and mortality of Leptospirosis: A systematic review. PLoS Neglected Tropical Diseases, 9: e0003898. DOI: https://www.doi.org/10.1371/journal.pntd.0003898.

Daud A, Fuzi NM, Arshad MM, Kamarudin S, Mohammad WM, Amran F, and Ismail N (2018). Leptospirosis seropositivity and its serovars among cattle in Northeastern Malaysia. Veterinary World, 11: 840-844. DOI: https://www.doi.org/10.14202/vetworld.2018.840-844.

De Brito T, Silva AM, and Abreu PA (2018). Pathology and pathogenesis of human leptospirosis: A commented review. Revista del Instituto de Medicina Tropical Sao Paulo, 60: DOI: https://www.doi.org/10.1590/S1678-9946201860023.

El Jalii IM, and Bahaman AR (2004). A review of human Leptospirosis in Malaysia. Tropical Biomedicine, 21: 113-119. Available at: https://pubmed.ncbi.nlm.nih.gov/16493403/

Ellis WA (2015). Animal leptospirosis. Current Topic in Microbiology and Immunology, 387: 99-137. DOI: https://www.doi.org/10.1007/978-3-662-45059-8_6.

Esteves LM, Bulhões SM, Branco CC, Carreira T, Vieira ML, Gomes-Solecki M, and Mota-Vieira L (2018). Diagnosis of human Leptospirosis in a clinical setting: Real-Time PCR high resolution melting analysis for detection of Leptospira at the onset of disease. Scientific Reports, 8: 9213. DOI: https://www.doi.org/10.1038/s41598-018-27555-2.

Garba B, Bahaman AR, Khairani-Bejo S, Zakaria Z, and Mutalib AR (2017). Retrospective study of Leptospirosis in Malaysia. Ecohealth, 14: 389-398. DOI: https://www.doi.org/10.1007/s10393-017-1234-0.

Garba B, Bahaman AR, Zakaria Z, Bejo SK, Mutalib AR, Bande F, and Suleiman N (2018). Antigenic potential of a recombinant polyvalent DNA vaccine against pathogenic leptospiral infection. Microbial Pathogenesis, 124: 136-144. DOI: https://www.doi.org/10.1016/j.micpath.2018.08.028.

Garba B, Habibullah SA, Saidu B, and Suleiman N (2019). Effect of mastitis on some hematological and biochemical parameters of Red Sokoto goats. Veterinary World, 12: DOI: https://www.doi.org/10.14202/vetworld.2019.572-577.

Goris MG, Leeflang MM, Loden M, Wagenaar JF, Klatser PR, Hartskeerl RA, and Boer KR (2013). Prospective evaluation of three rapid diagnostic tests for diagnosis of human Leptospirosis. PLoS Neglected Tropical Diseases, 7: e2290. DOI: https://www.doi.org/10.1371/journal.pntd.0002290.

Haake DA, and Levett PN (2015). Leptospirosis in humans. Current Topic in Microbiology and Immunology, 387: 65-97. DOI: https://www.doi.org/10.1007/978-3-662-45059-8_5.

Hagan JE, Moraga P, Costa F, Capian N, Ribeiro GS, Wunder Jr EA, Felzemburgh RD, Reis RB, Nery N, Santana FS et al. (2016). Spatiotemporal determinants of urban Leptospirosis transmission: Four-year prospective cohort study of slum residents in Brazil. PLoS Neglected Tropical Diseases, 10: e0004275. DOI: https://www.doi.org/10.1371/journal.pntd.0004275.

Hartskeerl RA, and Terpstra WJ (1996). Leptospirosis in wild animals. Veterinary Quarterly, 18: 149-50. Available at: https://www.tandfonline.com/doi/pdf/10.1080/01652176.1996.9694722

Al Kattan G, Bahaman AR, Bejo SK, Zakaria Z, and Garba B (2017). Serological And Molecular Prevalence of Leptospira Infection In Rat Populations In Kuala Lumpur. Austtralian Journal of Basic Applied Science, 11: 62-72. Available at: http://creativecommons.org/licenses/by/4.0/.

Jesse FF, Hambali IU, Abba Y, Lin CC, Chung EL, Bitrus AA, Abdullah AA, Balakrishnan KN, Bala JA, and Lila MA (2018). Effect of dexamethasone administration on the pathogenicity and lesion severity in rats experimentally inoculated with Orf virus (Malaysian isolates). Comparative Clinical Pathology, 27: 1227-1236. DOI: https://www.doi.org/10.1007/s00580-018-2726-1. 
Katz AR, Ansdell VE, Effler PV, Middleton CR, and Sasaki DM. (2001). Assessment of the Clinical Presentation and Treatment of 353 Cases of Laboratory-Confirmed Leptospirosis in Hawaii, 1974-1998. Clinical Infectious Diseases, 33: 1834-1841. DOI: https://www.doi.org/10.1086/324084.

Kishimoto M, Brown JD, Chung HH, and Howman S (2004). Leptospirosis misdiagnosed as pulmonary-renal syndrome. American Journal of Medical Sciences, 328: 116-120. DOI: https://www.doi.org/10.1097/00000441-200408000-00008.

Laras K, van Cao B, Bounlu K, Nguyen TK, Olson JG, Thongchanh S, Tran NV, Hoang KL, Punjabi N, Ha BK et al. (2002). The importance of Leptospirosis in Southeast Asia. American Journal of Tropical Medicine and Hygiene, 67: 278-86. DOI: https://www.doi.org/110.4269/ajtmh.2002.67.278.

Levett PN (2001). Leptospirosis Leptospirosis. Clinical Microbiology Review, 14(2): 296-326. DOI: https://www.doi.org/10.1128/CMR.14.2.296.

Lim JK, Murugaiyah VA, Ramli AS, Rahman HA, Mohamed NS, Shamsudin NN, and Tan JC (2011). A Case Study: Leptospirosis in $\begin{array}{llll}\text { Malaysia. } & \text { Infectious } & \text { Diseases, } & \text { 2(12): }\end{array}$ DOI: https://www.doi.org/10.9754/journal.wmc.2011.002764

McBride AJ, Athanazio DA, Reis MG, and Ko AI (2005). Leptospirosis. Current Opinion in Infectious Diseases, 18: 376-386. DOI: https://www.doi.org/10.1097/01.qco.0000178824.05715.2c.

Miotto BA, Tozzi BF, de Souza Penteado M, Guilloux AG, Moreno LZ, Heinemann MB, Moreno AM, Lilenbaum W, and Hagiwara MK (2018). Diagnosis of acute canine leptospirosis using multiple laboratory tests and characterization of the isolated strains. BMC Veteterinary Research, 14: 222. DOI: https://www.doi.org/10.1186/s12917-018-1547-4.

Radi MF, Hashim JH, Jaafar MH, Hod R, Ahmad N, Nawi AM, Baloch GM, Ismail R, and Ayub NI (2018). Leptospirosis outbreak after the 2014 major flooding event in Kelantan, Malaysia: A spatial-temporal analysis. American Journal of Tropical Medicine and Hygiene, 98: 1281-1295. DOI: https://www.doi.org/10.4269/ajtmh.16-0922.

Monahan AM, Callanan JJ, and Nally JE (2009). Review paper: Host-pathogen interactions in the kidney during chronic leptospirosis. Veterinary Pathology, 46: 792-799. DOI: https://www.doi.org/10.1354/vp.08-VP-0265-N-REV.

Musso D, and La Scola B (2013). Laboratory diagnosis of leptospirosis: A challenge. Journal of Microbiology, Immunology and Infection, 46: 245-252. DOI: https://www.doi.org/10.1016/j.jmii.2013.03.001.

Silva M, Camargo ED, Batista L, Vaz AJ, Brandao AP, Nakamura PM, and Negrao JM (1995). Behaviour of specific IgM, IgG and IgA class antibodies in human Leptospirosis during the acute phase of the disease and during convalescence. Journal of Tropical Medicine and Hygiene, 98: 268-272. Available at: https://pubmed.ncbi.nlm.nih.gov/7636924/.

Neela VK, Azhari NN, Joseph N, Mimie NP, Ramli SN, Mustapha NF, Ishak SN, Mohd-Taib FS, Yusof MA, Desa MN et al. (2019). An outbreak of leptospirosis among reserve military recruits, Hulu Perdik, Malaysia. European Journal of Clinical Microbiology and Infectious Disease, 38: 523-528. DOI: https://www.doi.org/10.1007/s10096-018-03450-6.

Niloofa R, Fernando N, de Silva NL, Karunanayake L, Wickramasinghe H, Dikmadugoda N, Premawansa G, Wickramasinghe R, de Silva HJ, Premawansa S et al. (2015). Diagnosis of Leptospirosis: Comparison between microscopic agglutination test, IgMELISA and IgM Rapid Immunochromatography Test. PLoS One, 10: e0129236. DOI: https://www.doi.org/10.1371/journal.pone.0129236.

Picardeau M (2013). Diagnosis and epidemiology of leptospirosis. Médecine et Maladies Infectieuses, 43: 1-9. DOI: https://www.doi.org/10.1016/j.medmal.2012.11.005.

Picardeau M, Bertherat E, Jancloes M, Skouloudis AN, Durski K, and Hartskeerl RA (2014). Rapid tests for diagnosis of leptospirosis: current tools and emerging technologies. Diagnostic Microbiology and Infectious Disease, 78: 1-8. DOI: https://www.doi.org/10.1016/j.diagmicrobio.2013.09.012.

Rafizah AN, Aziah BD, Azwany YN, Imran MK, Rusli AM, Nazri SM, Nikman AM, Nabilah I, Asma HS, Zahiruddin WM et al. (2013). A hospital-based study on seroprevalence of leptospirosis among febrile cases in northeastern Malaysia. International Journal of Infectious Disease, 17: 394-397. DOI: https://www.doi.org/10.1016/j.ijid.2012.12.012.

Ab Rahman MH, Hairon SM, Hamat RA, Jamaluddin TZ, Shafei MN, Idris N, Osman M, Sukeri S, Wahab ZA, Mohammad WM et al. (2018). Seroprevalence and distribution of leptospirosis serovars among wet market workers in northeastern, Malaysia: A cross sectional study. BMC Infectious Disease, 18: 569. DOI: https://www.doi.org/10.1186/s12879-018-3470-5.

Rawlins J, Portanova A, Zuckerman I, Loftis A, Ceccato P, Willingham AL, and Verma A (2014). Molecular detection of leptospiral DNA in environmental water on St. Kitts. International Journal of Environmental Research and Public Health, 11: 7953-7960. DOI: https://www.doi.org/10.3390/ijerph110807953.

Riefkohl A, Ramírez-Rubio O, Laws RL, McClean MD, Weiner DE, Kaufman JS, Galloway RL, Shadomy SV, Guerra M, Amador JJ et al. (2017). Leptospira seropositivity as a risk factor for mesoamerican nephropathy. International Journal of Occupational and. Environmental Health, 23: 1-10. DOI: https://www.doi.org/10.1080/10773525.2016.1275462.

Russell CD, Jones ME, O'Shea DT, Simpson KJ, Mitchell A, and Laurenson IF (2018). Challenges in the diagnosis of leptospirosis outwith endemic settings: A scottish single centre experience. Journal of Royal College of Physicians Edinburgh, 48: 9-15. DOI: https://www.doi.org/10.4997/JRCPE.2018.102.

Sukeri S, Idris Z, Zahiruddin WM, Shafei MN, Idris N, Hamat RA, Jamaluddin TZ, Osman M, Wahab ZA, and Daud A (2018). A qualitative exploration of the misconceptions, knowledge gaps and constructs of leptospirosis among rural and urban communities in Malaysia. PLoS One, 13: e0200871. DOI: https://www.doi.org/10.1371/journal.pone.0200871.

Tan WL, Soelar SA, Mohd Suan MA, Hussin N, Cheah WK, Verasahib K, and Goh PP (2016). Leptospirosis incidence and mortality in Malaysia. Southeast Asian Journal of Tropical Medicine and Public Health, 47: 434-440. Available at: https://pubmed.ncbi.nlm.nih.gov/27405126/

Tan XT, Amran F, Cheong KC, and Ahmad N. (2014). In-house ELISA screening using a locally-isolated Leptospira in Malaysia: determination of its cut-off points. BMC Infectious Disease, 14: 563. DOI: https://www.doi.org/10.1186/s12879-014-0563-7.

Tong SY, and Giffard PM (2012). Microbiological applications of high-resolution melting analysis. Journal of Clinical Microbiology, 
Torgerson PR, Hagan JE, Costa F, Calcagno J, Kane M, Martinez-Silveira MS, Goris MG, Stein C, Ko AI, and Abela-Ridder B (2015). Global Burden of Leptospirosis: Estimated in terms of disability adjusted life years. PLoS Neglected Tropical Diseases, 9: e0004122. DOI: https://www.doi.org/10.1371/journal.pntd.0004122.

Toyokawa T, Ohnishi M, and Koizumi N (2011). Diagnosis of acute leptospirosis. Expert Review of Anti-Infective Therapy, 9: 111121. DOI: https://www.doi.org/10.1586/eri.10.151.

Vanasco NB, Schmeling MF, Lottersberger J, Costa F, Ko AI, and Tarabla HD (2008). Clinical characteristics and risk factors of human leptospirosis in Argentina (1999-2005). Acta Tropica, 107: 255-258. DOI: https://www.doi.org/10.1016/j.actatropica.2008.06.007.

Victoriano AF, Smythe LD, Gloriani-Barzaga N, Cavinta LL, Kasai T, Limpakarnjanarat K, Ong BL, Gongal G, Hall J, Coulombe CA et al. (2009). Leptospirosis in the Asia pacific region. BMC Infectious Disease, 9: 147. DOI: https://www.doi.org/10.1186/14712334-9-147.

Vitale M, Agnello S, Chetta M, Amato B, Vitale G, Bella CD, Vicari D, and Presti VD (2017). Human Leptospirosis cases in Palermo Italy. The role of rodents and climate. Journal of Infection and Public Health, 11: 209-214. DOI: https://www.doi.org/10.1016/J.JIPH.2017.07.024.

Wittwer CT, Reed GH, Gundry CN, Vandersteen JG, and Pryor RJ (2003). High-resolution genotyping by amplicon melting analysis using LCGreen. Clinical Chemotherapy, 49: 853-860. DOI: https://www.doi.org/10.1373/49.6.853.

Wuthiekanun V, Chierakul W, Limmathurotsakul D, Smythe LD, Symonds ML, Dohnt MF, Slack AT, Limpaiboon R, Suputtamongkol Y, White NJ, et al. (2007). Optimization of culture of Leptospira from humans with leptospirosis. Journal of Clinical Microbiology, 45: 1363-1365. DOI: https://www.doi.org/10.1128/JCM.02430-06.

Yang HY, Hung CC, Liu SH, Guo YG, Chen YC, Ko YC, Huang CT, Chou LF, Tian YC, Chang MY et al. (2015). Overlooked risk for chronic kidney disease after Leptospiral infection: A Population-Based Survey and Epidemiological Cohort Evidence. PLoS Neglected Tropical Diseases, 9: e0004105. DOI: https://www.doi.org/10.1371/journal.pntd.0004105.

Zamri Z, Shaker AH, and Razman J (2012). Leptospirosis complicating with acute large bowel gangrene: A case report. Clinical Therapeutics, 163: 399-400. Available at: https://pubmed.ncbi.nlm.nih.gov/23099969/ 